\title{
Agentes de Saúde em Comunidades Urbanas
}

\section{Community-Based Health Workers in Urban Areas}

\author{
João Cláudio L. Fernandes ${ }^{1}$
}

FERNANDES, J. C. L. Community-Based Health Workers in Urban Areas. Cad. Sauide Públ., Rio de Janeiro, 8 (2): 134-139, abr/jun, 1992.

The employment of community-based health workers (CHWs) in primary health care projects is a widespread experience, mainly in Third World countries. However, it is important to differentiate between the rural and urban profiles of these professionals. The replacement of medical/odontological/psychological professionals by $\mathrm{CHWs}$ alone may represent a limited approach to primary health care problems, leading to the development of different health care patterns, depending on the social class they are addressed.

This paper points to need for the qualification of high-level health personnel also trying to identify the location of CHWs in this field, their technical specificity, as well as some difficulties observed in this practice.

Keywords: Communities; Primary Health Care; Community Health; Health Agents

\section{INTRODUÇÃO}

A utilização de agentes comunitários na atenção primária à saúde é uma experiência defendida pela maior parte das instituições ligadas a esta área e tem sido largamente incentivada pela Organização Mundial da Saúde. Não obstante o resultado positivo obtido em diversos projetos, a discussão sobre o perfil de atuação destes agentes estą presente na maioria dos debates de saúde comunitária, e uma definição clara e universal deste parece estar longe de ser alcançada. Isto decorre, possivelmente, da necessidade de adaptação deste modelo às realidades regionais onde são implantados, o que consideramos indispensável, particularmente no que se refere ao aspecto rural/urbano.

Harpham (1986), ao rever as concepções de atenção primária mais utilizadas atualmente, afirma que, tanto do ponto de vista operacional quanto conceitual, há o predomínio de uma abordagem rural, baseada em uma epidemiologia rural. De fato, a atuação de moradores treinados para realizar diagnósticos e terapêuti-

\footnotetext{
' Pasto de Saúde da Associação dos Moradores e Amigas do Bairro Barcellos. Travessa Flores, 4, Favela da Rrcinha, Rio de Janeiro, RJ, 22451-410, Brasil.
}

cas simplificadas tem sido tradicionalmente ligada a estas populações, para as quais o acesso a informações e aos serviços de saúde comuns apresenta obstáculos quase intransponíveis. Nestas regiōes, os indicadores de saúde apontam para altas taxas de morbi-mortalidade, particularmente infantil, provocadas principalmente por doenças infecciosas facilmente preveníveis ou curáveis mediante a execução de procedimentos relativamente simples. Para responder a este desafio de forma efetiva e eficiente, foram desenvolvidos, então, diversos programas, geralmente baseados na utilização de agentes comunitários, cujo objetivo é a melhoria destes indicadores. Trata-se, portanto, de uma abordagem eminentemente epidemiológica que tem obtido alguns resultados significativos, como, por exemplo, a redução do número de óbitos por diarréia nos lugares onde foram instituídos programas de TRO, aumento da cobertura vacinal, etc. Em função destes resultados, rapidamente este modelo passou a ser considerado como a grande alternativa para a melhoria das condições de saúde das populações dos países pobres e uma ferramenta indispensável para atingir o objetivo, defendido em Alma-Ata, de promover sauide para todos até $O$ ano 2000 (OMS/UNICEF, 1978). 


\section{A Atenção Primária e as Conjunturas Urbanas de Saúde}

Se, por um lado, esta estratégia representou um passo importante na diminuição da morbimortalidade em comunidades não atingidas pelos serviços de saúde, por outro, a não-discriminação de suas características específicas acabou conduzindo a um predomínio do pensamento epidemiológico nas práticas de saúde dirigidas às populações pobres. Este fato, aliado à carência de análises mais aprofundadas dos aspectos político-ideológicos associados a este modelo, propiciou, como conseqüência, um relativo distanciamento da perspectiva de conquista do direito a um atendimento individualizado e de boa qualidade, o que, nos países pobres, se restringe às classes de maior poder aquisitivo. Não se trata, portanto, de negar a utilidade daquelas ações, mas de apontar a necessidade de localizá-las dentro de uma conjuntura político-sanitária determinada.

Se a premissa de que é um direito de cidadania o acesso a um atendimento pessoalizado e eficiente é correta em relação a qualquer indiví- duo, rural ou urbano, pobre ou rico, nas regiōes urbanas ela parece particularmente relevante. De fato, em países como o Brasil, encontramos em muitas cidades uma quantidade de recursos materiais e humanos suficiente para $o$ atendimentro adequado de uma boa parte da população. Segundo relatório da PWR (1989), o país dispōe de recursos assistenciais quantitativamente satisfatórios, apesar das distorções regionais. No entanto, estes recursos encontram-se dispersos, desorganizados e mal distribuidos, levando a um déficit assistencial de grandes proporções. Como exemplos, podemos citar o indice de desemprego nas diversas categorias da área de saúde, a relação médico/ habitante em várias capitais do país (Figura 1), o absenteísmo e o desperdício de recursos em muitas unidades e programas. Em relação a este último ponto, o mesmo relatório estima, na rede pública, uma capacidade ociosa de $40 \%$ (PWR, 1989). Parece faltar, portanto, um planejamento organizado e racionalizado, e o desenvolvimento de políticas corretas de recursos humanos, tanto ou mais do que propriamente estes recursos.

FIGURA 1 - Distribuição de Médicos por Habitantes

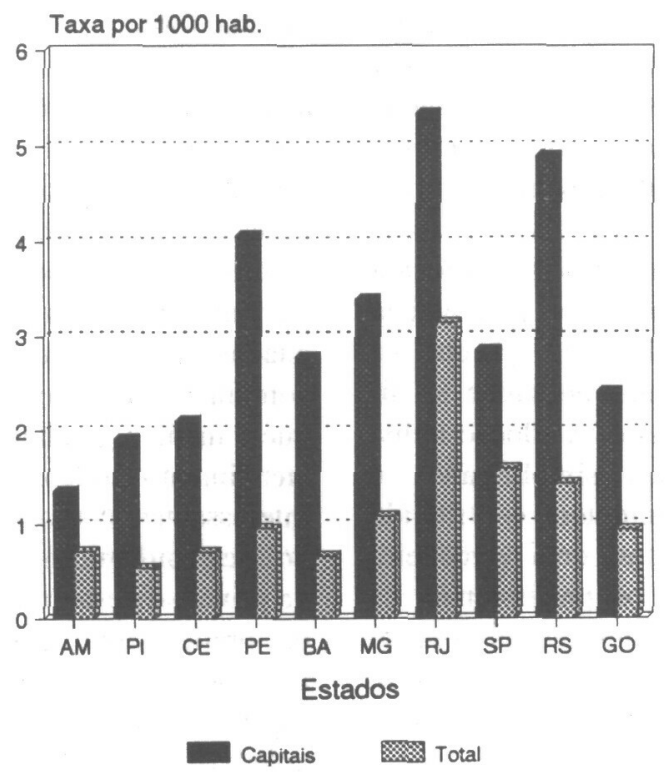

Fonte: CFM/IBGE, AEB- 1986/Nescon-UFMG 
Desta forma, a implantação de projetos de saúde, em áreas urbanas postergadas, baseados na substituição da assistência médica/odontológica/psicológica etc. pelo trabalho de agentes de saúde poderia servir simplesmente para adaptar e perpetuar um modelo assistencial desigual e discriminatório, caracterizado por duas formas de organização distintas: uma dirigida às classes ricas, baseadas na atuação de profissionais altamente especializados e na larga utilização de tecnologia sofisticada, e outra voltada às populaçōes carentes, baseada em recursos simplificados e na atuação educativo/epidemiológica.

\section{A Assistência Médica na Atenção Primária à Saúde}

Por outro lado, a partir da utilização de agentes de saúde nos programas de assistência, muitos planejadores e profissionais passaram a questionar a real necessidade da presença do médico nas unidades de atenção primária. Baseados no fato de que em todos esses serviços há uma nítida prevalência de determinadas doenças (diarréias, verminoses, infeç̧ōes respiratórias, hipertensão arterial etc.) que poderiam ser facilmente rastreadas e atendidas por pessoal não médico devidamente treinado, e que as situações de saúde mais complexas poderiam ser identificadas e encaminhadas a hospitais por estas pessoas, criou-se uma percepção bastante difundida de que o médico deveria ter uma atuação, no máximo, de treinamento e supervisão junto aos agentes. Esta visão é ainda reforçada através de um discurso que coloca a prática médica ambulatorial como paternalista e, em última instância, ineficaz, já que os determinantes dos problemas de saúde se situam ao nível da coletividade. A adoção indiscriminada destes métodos simplificados $\mathrm{e}$ massificados de atendimento tem contribuído para gerar, em alguns casos, uma verdadeira crise de identidade entre os profissionais de atenção primária, onde muitas vezes confundem-se, numa prática semelhante, médicos, enfermeiras, agentes de saúde e até mesmo psicólogos e assistentes sociais.

Esta concepção, na verdade, retrata um empobrecimento na percepção do processo de saúde/ doença, cuja origem se situa nos instrumentais de análise comumente empregados pelos profissionais envolvidos. $\mathrm{Na}$ medida em que os trabalhos de saúde comunitária privilegiam basicamente a epidemiologia, utilizando algumas vezes também uma abordagem política ambas formas de compreensão do coletivo ao nivel do atendimento individual, acabam tendo que se restringir à fisiopatologia tradicional como a única ferramenta disponivel para a abordagem do paciente. Ocorre que, como descreve Foucault (1977), esta fisiopatologia, alicerce básico do ensino médico universitário, foi criada e desenvolvida principalmente no interior dos hospitais, onde os casos complexos encontram sua possibilidade de estudo e elucidação, e cujo desenvolvimento exige uma infraestrutura que somente os hospitais, particularmente os universitários, e seus laboratórios podem fornecer.

Deste modo, o interesse físiopatológico, na prática ambulatorial, é extremamente limitado, $\mathrm{e}$ as queixas e doenças que predominam nesta área logo se tornam, a partir desta abordagem, banais, monótonas e repetitivas. Tão repetitivas que logo passam a ser facilmente identificadas e medicadas, segundo um protocolo igualmente banal de tratamento. Conseqüentemente, qualquer pessoa razoavelmente treinada logo passa a dominar esta metodologia, executando-a da mesma forma, ou até melhor, que o médico. Além disto, a abordagemn fisiopatológica na atenção primária apresenta outras limitações, como a reincidência das mesmas patologias, a dificuldade de conseguir os medicamentos necessários, a frustração com o não-cumprimento das recomendaçôes médicas por parte do paciente etc. Talvez estas questões, além das citadas anteriormente, ajudem a explicar o fato, comum nos projetos de saúde comunitária, de que o médico geralmente acaba abandonando o atendimento clínico, reservando-se funções mais interessantes, como a coordenação e a atuação política/epidemiológica ou educativa. $O$ resultado principal deste processo é o empobrecimento da prática clínica, com a execução de um atendimento curativo superficial e limitado, na esperança de que, resolvidos os problemas coletivos, estas demandas sejam solucionadas de forma mais concreta.

No entanto, à medida que, aprofundando os conceitos de saúde sugeridos em Alma-Ata, a 
saúde passa a ser considerada como direito de todos, inclusive do ponto de vista qualitativo, $\mathrm{e}$ definida como bem estar, introduz-se a necessidade de incorporar à abordagem individual outros conhecimentos, além da fisiopatologia, que ajudem a compreender o adoecimento e o indivíduo de um modo mais amplo. Se esta compreensão ampliada poderia favorecer em certas situações a atuação hospitalar, na prática da atenção primária ela toma-se fundamental, uma vez que os pacientes atendidos trazem à consulta toda a sua complexidade histórica e existencial, e demandam uma atenção que, na maior parte das vezes, se distancia da questão especificamente fisiopatológica e que nem sempre pode ser reduzida aos problemas sociais e coletivos. Esta realidade pode ser avaliada indiretamente pelo alto índice de diagnósticos pouco conclusivos encontrados na prática ambulatorial, como mostra a Tabela 1, onde observamos que quase $1 / 4$ do total de diagnósticos efetuados referem-se a estados mórbidos mal-definidos, e cerca de $3 \%$ deste total estão relacionados a problemas da esfera emocional. É interessante observar, neste aspecto, que tanto o modelo assistencial dirigido às classes pobres quanto o destinado às classes ricas mostram-se igualmente limitados, o primeiro buscando priorizar o aspecto coletivo/epidemiológico, enquanto o segundo procura ater-se à exploração fisiopatológica e à consequiente medicalização.
O campo de conhecimento da atenção primária não está, portanto, limitado ao binômio epidemilogia/fisiopatologia nem se refere unicamente às classes pobres. Significa, na verdade, um nivel de atenção específico na hierarquia do Sistema de Saúde, caracterizado por uma maior abrangência na percepção do fenômeno do adoecimento e, conseqüentemente, uma maior variedade de possibilidades terapêuticas. Tratase, portanto, de um conhecimento razoavelmente diferenciado das práticas de saúde pública, por um lado, e hospitalares, por outro, embora utilize freqüentemente estes dois instrumentais. Por consequiência, a atenção primária demanda a capacitação de profissionais que tenham acesso a este saber de uma forma estruturada e tecnicamente correta, o que, na nossa opinião, corresponderia, no campo institucional, a uma área de especialização médica.

\section{Algumas Conclusãos Sobre o Perfil do Agente de Saúde}

Estes conceitos colocam novas necessidades para o correto estabelecimento do perfil de trabalho dos agentes de saúde, particularmente nos meios urbanos. Isto é, na medida em que se defende a prática médica de atenção primária como um campo específico e especializado de atuação, as atribuições e características que identificam o espaço profissional destes agentes passa a necessitar de novas definições.

TABELA 1 - Diagnósticos mais Freqüentes*

\begin{tabular}{|l|c|}
\hline Estado mórbido mal-definido & $24 \%$ \\
Doenças da mama e outras do ap. genito-urinário & $9 \%$ \\
Acidentes, envenenamentos e violència & $8 \%$ \\
Outras helmintíases & $5 \%$ \\
Gripe & $4 \%$ \\
Demais doenças do ap. osteomuscular e do tec. conjuntivo & $3 \%$ \\
Neurose, transtomos da personalidade e outras doenças mentais & $3 \%$ \\
Infeç̧ões respiratórias agudas & $3 \%$ \\
Demais doenças do aparelho digestivo & $3 \%$ \\
Demais doenças do sistema nervoso e orgãos dos sentidos & $3 \%$ \\
DPOC & $3 \%$ \\
\hline Total & $69 \%$ \\
\hline
\end{tabular}

* CEME, Plano Diretor de Medicamentos, $1^{1}$ fase, 1972-1978. Análise disgnóstico, vol. III, Brasilia, 1973, citado por H. Cordeiro, A Indústria de Saúde no Brasil (Rio de Janeiro: Graal, 1980). 
Em relação a este aspecto, a primeira constatação a ser feita é da necessidade de pessoal de nível médio para a execução de procedimentos necessários ao funcionamento das unidades de atenção primária. Estes procedimentos podem ser divididos em dois aspectos: um aspecto administrativo/burocrático (secretaria, manutenção de arquivo, controle de estoque etc.) e um aspecto técnico/assistencial no campo das práticas de enfermagem (coleta de exames, préconsulta, curativos, injeção, nebulização, aferição de dados vitais, retirada de pontos etc.) e da higiene oral (escovação e aplicação de flúor, instrumentação e manipulações simples). Em segundo lugar, ao nivel das práticas educativo/ epidemiológicas, parecem existir algumas vantagens na atuação de agentes locais, em relação aos outros profissionais, em termos da capacidade de interagir positivamente com os moradores em discussões (sala de espera, conversas, debates em escolas etc.). $O$ trabalho de percepção, investigação e captação de casos importantes do ponto de vista individual ou epidemiológico, e a elaboração de propostas de atuação, também são extremamente facilitados por estes agentes, devido ao conhecimento que possuem da população e da área, além do favorecimento da integração do serviço de saúde com outras organizações locais e a comunidade em geral. Devido ao fato destes profissionais morarem na comunidade, podem atuar também de forma decisiva em situações de emergência, dando os primeiros socorros e, eventualmente, executando procedimentos terapêuticos, quando não é possível a presença do médico. Para isto, é necessário, evidentemente, que tenham uma formação técnica adequada.

Por outro lado, são percebidas algumas dificuldades neste modelo. Se, por um lado, os agentes de saúde apresentam uma característica positiva de interligação entre a equipe profissional e a comunidade, servem, por outro, freqüentemente como anteparo das cobranças e insatisfações da população com relação ao serviço. Além disso, passam a ocupar um lugar de poder que os discrimina do restante da população, no que se refere ao serviço de saúde, o que gera, algumas vezes, conflitos pessoais e problemas na unidade. Absorvem, ainda, uma forte pressão de pessoas da comunidade para obter favoreci- mentos e driblar normas no atendimento, o que provoca um grande desgaste para estes profissionais. A integração destes ao restante da equipe também deve ser cuidadosamente analisada. Como nos lembra Ramos et al. (1989), por trás da denominação genérica de profisssionais de saúde, existem claras divisões de ordens técnica e hierárquica que acarretam também níveis diferenciados de poder no interior das unidades. Neste contexto, os agentes podem ter uma participação passiva, assimilando o discurso dos técnicos de fora e reproduzindo-o de forma mais ou menos mecânica, impossibilitados de interagir ou se contrapor a esta ordem. Embora estas questões não invalidem a positividade deste modelo, colocam a necessidade de um constante acompanhamento e avaliação do trabalho, e demandam, sem dúvida, a realização de estudos mais aprofundados a este respeito.

Finalmente, gostariamos de ressaltar que em situações particularmente importantes do ponto de vista epidemiológico, para as quais são organizadas campanhas ou programas de massa, pode-se recorrer ao treinamento de moradores voluntários para atuar especificamente na questão em foco. Trata-se, neste caso, de desenvolver uma abordagem predominantemente epidemiológica, mas limitada a um determinado problema, o que, longe de descaracterizar o perfil de trabalho da atenção primária à saúde, reforça seu aspecto de abrangência e diversificação.

\section{RESUMO}

FERNANDES, J. C. L. Agentes de Saúde em Comunidades Urbanas. Cad. Saúde Públ., Rio de Janeiro, 8 (2): 134-139, abr/jun, 1992.

A utilização de agentes comunitários nos programas de atenção primária à saúde é uma experiência amplamente difundida, principalmente nos paises do Terceiro Mundo. É importante, entretanto, discriminar o perfil de atuação destes agentes em função da área onde atuam, principalmente no que diz respeito às diferenças entre o meio rural e o 
urbano. A simples substituição de profissionais de medicina, odontologia, psicologia etc, por agentes comunitários pode significar uma abordagem limitada do conceito de atenção primária, levando ao desenvolvimento de modelos assistenciais distintos, determinados em função da classe social a que se dirigem.

Neste artigo, é apontada a necessidade de formação de recursos humanos de nível superior para a atenção primária à saúde, buscando-se também identificar o lugar dos agentes comunitários nesta área, sua especificidade técnica, bem como alguns obstáculos percebidos neste campo profissional.

Palavras-Chave: Comunidade; Atenção Primária à Saúde; Saúde Comunitária; Agentes de Saúde

\section{REFERÊNCIAS BIBLIOGRÁFICAS}

FOUCAULT, M., 1977. O Nascimento da Clinica. Rio de Janeiro: Forense Universitária.

HARPHAM, T., 1986. Health and the urban poor. Health Policy and Planning, 1: 5-18.

PWR - Brasil (Pan-American Health Organization/ World Health Organization Representative), 1989. Brasil - Condições de Saúde (Documento Preliminar), mimeo, Brasília: PAHO.

RAMOS, C. L.; MELO, J. A. C. \& SOARES, J. C. R., 1989. Quem educa quem? Repensando a relação médico-paciente. In: Demandas Populares, Politicas Públicas e Saúde (N. R. Costa; C. L. Ramos; M. C. de S. Minayo \& E. N. Stotz, orgs.), pp. 146-164, Petrópolis: Vozes. 